\title{
Octave Programming Language
}

National Cancer Institute

\section{Source}

National Cancer Institute. Octave Programming Language. NCI Thesaurus. Code C69303.

An interpreted programming language for performing numerical computations for scientific computing. 